\title{
LATE SURGICAL COMPLICATIONS AFTER GASTRIC BY-PASS: A LITERATURE REVIEW
}

\author{
Complicações cirúrgicas tardias após bypass gástrico: revisão da literatura
}

Mariano PALERMO ${ }^{1}$, Pablo A. ACQUAFRESCA ${ }^{1}$, Tomasz ROGULA ${ }^{2}$, Guillermo E. DUZA ${ }^{1}$, Edgardo SERRA ${ }^{1}$

From the ${ }^{1}$ Division of Bariatric Surgery - CIEN-DIAGNOMED - affiliated to the University of Buenos Aires, Buenos Aires, Argentina and ${ }^{2} \mathrm{Cleveland}$ Clinic Foundation Bariatric and Metabolic Institute, Cleveland, $\mathrm{OH}, \mathrm{USA}$.

HEADINGS - Postoperative complications. Follow-up studies. Gastric bypass. Anastomosis, Roux-en-Y. Obesity.
ABSTRACT - Introduction: Gastric bypass is today the most frequently performed bariatric procedure, but, despite of it, several complications can occur with varied morbimortality. Probably all bariatric surgeons know these complications, but, as bariatric surgery continues to spread, general surgeon must be familiarized to it and its management. Gastric bypass complications can be divided into two groups: early and late complications, taking into account the two weeks period after the surgery. This paper will focus the late ones. Method: Literature review was carried out using Medline/PubMed, Cochrane Library, SciELO, and additional information on institutional sites of interest crossing the headings: gastric bypass AND complications; follow-up studies AND complications; postoperative complications AND anastomosis, Rouxen-Y; obesity AND postoperative complications. Search language was English. Results: There were selected 35 studies that matched the headings. Late complications were considered as: anastomotic strictures, marginal ulceration and gastrogastric fistula. Conclusion: Knowledge on strategies on how to reduce the risk and incidence of complications must be acquired, and every surgeon must be familiar with these complications in order to achieve an earlier recognition and perform the best intervention.

\section{Correspondence: \\ Mariano Palermo \\ E-mail: palermomd@msn.com \\ Financial source: none \\ Conflicts of interest: none \\ Received for publication: 15/06/2014 Accepted for publication: 27/11/2014}

DESCRTORES - Complicações pósoperatórias. Seguimento. Derivação gástrica. Anastomose em Y-de-Roux. Obesidade.
RESUMO - Introdução: O bypass gástrico é hoje o procedimento bariátrico mais realizado, mas, apesar disso, várias complicações podem ocorrer com variada morbimortalidade. Provavelmente todos os cirurgiões bariátricos conhecem essas complicações, mas como a cirurgia bariátrica continua a se espalhar, o cirurgião geral deve estar familiarizado com essas complicações e seu manuseio. As complicações do bypass gástrico podem ser divididas em dois grupos: as precoces e tardias, tendo em conta o período de duas semanas após a operação. Este artigo irá focar as tardias. Método: Foi realizada revisão da literatura utilizando as bases Medline/PubMed, Cochrane Library, SciELO, e informações adicionais sobre sites institucionais de interesse cruzando os descritores: bypass gástrico AND complicações; seguimento AND complicações; complicações pós-operatórias AND anastomose, Roux-en-Y; obesidade AND complicações pós-operatórias. A língua usada para a busca foi o inglês. Resultados: Foram selecionados 35 estudos que combinavam com os descritores. As complicações tardias foram consideradas como: estenose de anastomose, ulceração marginal e fístula gastrogástrica. Conclusão: O conhecimento sobre as estratégias de como reduzir o risco e incidência das complicações deve ser adquirido ao longo do tempo, e cada cirurgião deve estar familiarizado com essas complicações, a fim de reconhecê-las precocemente e realizar a melhor intervenção.

\section{INTRODUCTION}

A mong all the bariatric procedures, the gastric bypass is the most frequently performed ${ }^{16}$. It belongs to the group of combined procedures because it generates restriction and malabsorption.

The restriction is generated by cutting the proximal stomach, thereby reducing its volume and creating a pouch of approximately 10 to $25 \mathrm{ml}$, leaving the rest of the stomach excluded.

In the other hand, the malabsorption is generated by dividing the small intestine into an alimentary limb (Roux limb) and a biliopancreatic limb. The alimentary limb of Roux-en-Y is created by dividing the jejunum $50 \mathrm{~cm}$ below the duodenojejunal ligament. Then the alimentary limb is measured and a side-to-side stapled jejunojejunostomy is created, typically $150 \mathrm{~cm}$ below the gastrojejunal anastomosis.

Despite of it well documented safety $2,8,9,27,33,38$, several complications can occur with varying degrees of morbidity and mortality risk. These complications includes: early anastomotic or staple line leaks, gastrointestinal bleeding, intestinal obstruction ${ }^{4}$, and late complications - anastomotic strictures, marginal ulceration, gastro-gastric fistula and less common, incorrect Roux limb reconstruction. 


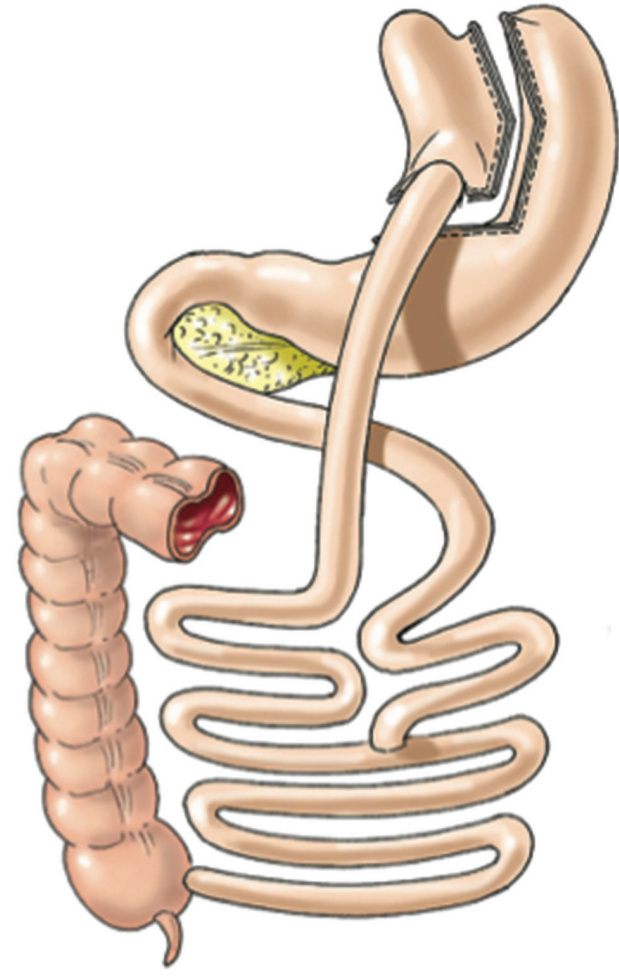

FIGURE 1 - Roux-en-Y gastric by pass (Laparoscopic Gastrointestinal Surgery. Palermo, Gimenez, Gagner. Cadiere and Dapri chapter) AMOLCA 2014

METHOD

Literature review was carried out using Medline/PubMed, Cochrane Library, SciELO, and additional information on institutional sites of interest crossing the headings: gastric bypass AND complications; follow-up studies AND complications; postoperative complications AND anastomosis, Roux-en-Y; obesity AND postoperative complications. Search language was English. There were selected 35 studies that matched the headings. Late complications included: anastomotic strictures, marginal ulceration and gastrogastric fistula.

\section{Anastomotic strictures}

There are two potential sites of strictures: thejejunojejunostomy and the gastrojejunostomy, being the latter the most common place of occurance ${ }^{24,42}$. It is reported in $5-27 \%$ of cases, typically within 90 days after surgery. The symptoms usually consist on persistent or worsening postprandial vomiting with or without pain.

The cause of stricture formation is not complete clear, the possible mechanisms include ischemia causing scarring, non-ischemic excessive scar formation, recurrent marginal ulceration, tension or malposition of the anastomosis, and surgical technique. Among the technical factors that can contribute to increased stricture formation are type of stapler used (circular vs linear), stapler size, handsewing, and surgeon experience.

Circular staplers offer surgeons a reproducible anastomosis, which eliminates any technique-dependent variability that might make it difficult to scientifically assess the effect of anastomotic size on incidence of stenosis and on the eventual weight loss resulting from gastric bypass surgery. The incidence of gastrojejunostomy stenosis in laparoscopic RYGB (LRYGB) using a 21 - versus $25-\mathrm{mm}$ circular stapler has been studied and it has been reported an increase of $29.6 \%$ in the lumen with the $25 \mathrm{~mm}$ stapler compared with the $21 \mathrm{~mm}$ stapler, reducing significantly the stenosis rates by one-half, and significantly delayed the onset of symptoms.

In contrast, other authors advocate for the use of a 21 $\mathrm{mm}$ stapler instead of the $25 \mathrm{~mm}$. They argued that restrictive procedures fail when the stoma is too wide. And also the stapler of $21 \mathrm{~mm}$ is less difficult to insert through the abdominal wall and small intestine, but, more importantly, because the small diameter of the anastomosis delays gastric pouch emptying and consequently increases weight loss in the long-term ${ }^{1}$.

Another factor that has shown to reduce the incidence of strictures is the construction of the gastrojejunostomy by hand-sewn. Comparative studies of the circular mechanical anastomosis versus a hand-sewn anastomosis have shown a significant increase in stenosis rates in the circular stapler group (31\% vs $3 \%)^{41}$.

This latter factor probably explain why it has been noted that strictures are substantially more frequent with the laparoscopic than the open approach ${ }^{18,23}$. It is for this very reason that robotic surgery could play a key role in the future by combining minimally invasive approach of the laparoscopic surgery and the possibility to perform hand-sewn anastomosis.

Linear staplers are also used for construction of the gastrojejunostomy. The reported stricture rate with this technique varies between $3.1 \%$ and $6.8 \%$, seemingly lower than the rate quoted for circular staplers ${ }^{5,27}$.

Routine performance of early postoperative upper gastrointestinal series would not seem to help predict the occurrence or progression to strictures ${ }^{6}$. Studies reported that a positive upper gastrointestinal series are $100 \%$ specific for the presence of stricture, whereas its sensitivity and negative predictive value is poor, making it unsatisfactory in definitively excluding the diagnosis. Marginal ulcerations can also produce the same clinical symptoms of stenosis and can even be the cause, therefore endoscopy is considered the preferred diagnostic procedure and has the added benefit of being therapeutic.

Several studies have shown that endoscopic balloon dilation is the first step of treatment ${ }^{24,37}$. Findings have shown that $17 \%$ to $67 \%$ of cases responded to the first dilation, whereas $3 \%$ to $8 \%$ of cases required three or more dilations. The dilation can be performed using pneumatic balloons or Savary-Gilliard bougies.

Late scarring and fibrosis at the anastomotic stricture would be a prohibitive factor and put the patient at increased risk of perforation during dilatation.

A graded classification of anastomotic strictures defined by endoscopy and their related management has been proposed by some authors as it is described as follows (Table 2$)^{39}$ :

TABLE 2 - Post-LRYGB gastrojejunostomy strictures endoscopically graded

\begin{tabular}{|c|c|}
\hline Grade & Strictures characteristics \\
\hline I & $\begin{array}{l}\text { Mild stenosis, which will allow a } 10.5-\mathrm{mm} \text { endoscope to } \\
\text { pass }\end{array}$ \\
\hline II & $\begin{array}{l}\text { Moderate stenosis, which will accommodate an } 8.5-\mathrm{mm} \\
\text { pediatric endoscope }\end{array}$ \\
\hline III & Severe stenosis, through which a guide-wire can be passed \\
\hline IV & $\begin{array}{c}\text { Complete/near-complete obstruction, which is non } \\
\text { traversable }\end{array}$ \\
\hline
\end{tabular}

Grade I: Mild stenosis can be managed by pneumatic dilation up to $16-18 \mathrm{~mm}$ and a second session for evaluation. The majority of patients do not require additional dilations.

Grade II: Moderate stenosis are usually managed by initial pneumatic dilation up to $15-\mathrm{mm}$. And a second session 
should be scheduled 2 weeks later, in which SavaryGilliard bougies are used (15-18 $\mathrm{mm}$ ).

Grade III: Severe stenosis should be managed by careful passage of a guide wire, over which a 6-mm CRE balloon is advanced, inflated for 60 seconds, and then withdrawn. Further dilation in the same sitting should not exceed a $10 \mathrm{~mm}$ sized balloon. The patient should be then scheduled for subsequent endoscopy in the fluoroscopy suite $1-2$ weeks later. In that sitting, dilation is started with a $10-\mathrm{mm}$ CRE balloon. If, following this pneumatic dilation, the stricture allows traversing with the endoscope $(10.5 \mathrm{~mm})$, further dilation with Savary-Gilliard bougies up to $15 \mathrm{~mm}$ may be attempted; otherwise, a third session must be scheduled for that purpose.

Grade IV: Initial dilation should not be attempted in this group. These patients should be referred for surgical revision of their anastomosis.

In the rare instance of failure of the endoscopic technique, an operative approach may be justified. Laparoscopic revision of a strictured anastomosis is a technically challenging procedure because of adhesion formation and difficulties in anatomical identification. An antecolic antegastric route of the Roux limb may make this attempt easier ${ }^{11}$.

Gastrojejunostomy strictures following RYGB are a relatively common complication, especially when stapled anastomosis are performed. The symptoms usually consist on postprandial vomiting with or without pain. The initial diagnostic and therapeutic attempt should be flexible endoscopy with concomitant pneumatic balloon dilation to the maximal diameter safe. A planned repeat session should be scheduled two weeks later with the intent of secondary dilation unless the anastomosis is viewed to be widely open.

\section{Marginal ulceration}

It is known as marginal ulceration the appearance of a peptic ulcer at the jejunal mucosa near the site of the gastrojejunal anastomosis. Marginal ulceration has been reported to be the most commonly found abnormality on endoscopy in symptomatic patients who underwent LRYGB ${ }^{50}$. It is diagnosed in $1 \%$ to $16 \%$ of patients s, $^{6,32}$.

Factors predisposing patients to marginal ulceration are unclear and have not been completely revealed ${ }^{23}$, but the origin is likely multifactorial. Several factors, including pouch size and orientation, mucosal ischemia, staple-line disruption and gastrogastric fistula (which allows the retrograde reflux of acid through the fistula), foreign body reaction and exogenous substances have been all implicated as potential causes ${ }^{26}$. Other intrinsic factors, such as hormonal and metabolic, versus extrinsic factors, such as tobacco and non-steroidal anti-inflammatory drug use have also been suggested.

Recently, it has been shown that the presence of Helicobacter pylori infection preoperatively may correlate with the development of a marginal ulceration in the postoperative period possibly suggesting a causative role for this organism ${ }^{21}$. Patients who present with upper gastrointestinal symptoms should undergo endoscopy before gastric bypass and should be treated if Helicobacter pylori is diagnosed. However, some authors believe that the prevalence of it in patients undergoing RYGB is similar to that in the general population, and that preoperative Helicobacter pylori testing and treatment does not decrease the incidence of anastomotic ulcer or pouch gastritis.

Larger pouch size ( $>50 \mathrm{~mL}$ ) and orientation have been thought to predispose patients to marginal ulceration and reducing its size has been shown to decrease its incidence. Studies have shown that creating a pouch limited to the cardia can result in a $0.6 \%$ marginal ulceration rate at 3 -year follow-up. Thus, larger pouch size was postulated early on to be correlated with increased acid production, leading to increased incidence of marginal ulcers.
A mechanism in which less acid reaches the antrum, leading to excessive stimulation of antral gastrin-secreting cells and higher gastrin levels, has been proposed ${ }^{42}$. Later investigators showed that little, if any, gastric acid is produced in the pouch ${ }^{37}$. However, the significant decrease in acid secretion after gastric bypass may not be universal and acid secretion could contribute in some patients with marginal ulceration (even though gastric acid secretion is nearly absent in most patients after gastric bypass, $43 \%$ of the patients can have a low $\mathrm{pH}$ within the pouch $)^{10}$.

An interesting finding is that serum gastrin levels are found to be universally low after gastric bypass. It seems that gastric acid secretion is primarily stimulated by gastrin in most obese patients; but, in patients who continue to have low gastric $\mathrm{pH}$ after surgery, vagal innervation may be the primary stimulus for acid secretion, putting them at higher risk for marginal ulceration. This role of acid secretion in developing marginal ulceration is supported by evidence that acid suppression alone is effective in healing most marginal ulcerations ${ }^{20}$

Another precipitating factor for marginal ulceration after LRYGB may be the prolonged irritation by foreign material, such as non-absorbable sutures at the gastrojejunostomy. Studies have been published comparing the incidence of marginal ulceration associated with the use of non-absorbable sutures versus absorbable ones and they found a significant decrease in incidence from $2.6 \%$ to $1.3 \%$, respectively ${ }^{5}$. Local ischemia has also been suggested as a cause of marginal ulceration, although it might more commonly lead to the development of stricture formation.Tobacco use is also an important factor in the development of ulcer disease. Studies have shown significant compromise of the gastric mucosal barrier and impaired wound healing associated with smoking ${ }^{41}$. Decreased tissue oxygenation has been proposed as the factor responsible for the impaired wound healing. It is important to remember that the jejunum, unlike the native duodenum, does not possess an innate acid buffer, and this is probably the most important contributor to the development of marginal ulceration at the gastrojejunostomy.

Timing and presentation of marginal ulceration after LRYGB vary widely. The diagnosis can occur within three months of surgery in $30 \%$ of the cases, between four and 12 months in $23 \%$, and after 12 months in $47 \%$ of the patients ${ }^{23}$.

In patients with a marginal ulcer, epigastric pain is the most common presenting symptom and is frequently the only symptom. However, patients may present with nausea and vomiting, dysphagia or bleeding from their ulcers which can lead to fatigue due to chronic anemia. Often, symptoms of marginal ulcer are confused with common postoperative complaints related to overeating.

In the presence of these symptoms in a patient who has gone under RYGB, the endoscopy should be performed to achieve the diagnosis ${ }^{30}$. In addition to marginal ulceration, postoperative endoscopy for symptoms after LRYGB may also reveal stenosis of the gastrojejunostomy or a gastrogastric fistula (although many physicians treat the symptomatic patients empirically with acid-blocking agents and do not perform diagnostic endoscopy). Late presentation of gastrointestinal bleeding at the gastrojejunostomy is most commonly associated with marginal ulceration ${ }^{6}$.

Regarding to the treatment, this is primarily medical consisting of anti-secretory therapy with proton pump inhibitors and sucralfate. In case of presence of a gastrogastric fistula surgery must be performed.

Most cases of marginal ulceration respond to proton pump inhibitors, $\mathrm{H} 2$-blockade or sucralfate therapy. If not treated promptly, marginal ulceration may lead to stricture formation and gastric pouch outlet obstruction, which will require endoscopic dilation. Unlike the more common peptic ulcers, these lesions tend to require prolonged therapy, 
usually for three to four months, and repeat endoscopy is recommended to confirm ulcer resolution.

An attempt should be made to identify the causative factor if present, such as NSAID use, smoking, or a remnant suture, which should then be managed accordingly. Occasionally, revision of the gastrojejunostomy anastomosis will be required for patients with persistent symptoms and ulceration despite aggressive medical therapy

In case of acute presentation with perforation, surgery must not be delayed. The incidence of this event is estimated in $0.85 \%$. Besides the traditional treatment with wash out of the abdominal cavity and suturing of the perforation, techniques with endoscopic suturing devices and omental patch repairs have been described ${ }^{25}$.

In conclusion, patients with upper gastrointestinal symptoms after RYGB warrant endoscopy regardless of time elapsed since the original operation. Abnormalities are found frequently in this population, and future therapy can be tailored based on endoscopic findings. The etiology of marginal ulceration remains an area of considerable debate. Although medical therapy is successful in most patients who develop a marginal ulcer after RYGB, a small number of patients will require operative revision for intractable ulcers.

\section{Gastro-gastric fistula}

A gastro-gastric fistula (GGF) is an abnormal communication between the gastric pouch and the excluded stomach. It is an uncommon but potentially important complication after divided LRYGB, with an incidence ranging between $1.5 \%$ and $6.0 \%{ }^{22}$.

Historically, the early open RYGB procedures involved the creation of a non-divided or partially divided gastric pouch ${ }^{15,21}$. GGF rates of $49 \%$ were reported after primary RYGB when the pouch and stomach were stapled in continuity or partially divided. Following complete transection of the gastric segments significant reduction in the incidence of GGF to $2.6 \%$ were reported, with further reduction with the use of jejunal limb interposition proton pump inhibitors ${ }^{36}$. These surgical techniques minimize the incidence of GGF formation, but do not eliminate it.

The most common symptom of GGF is inadequate weight loss or weight gain. However, intractable marginal ulceration, recurrent upper gastrointestinal hemorrhage, pain and stricture formation can all herald the presence of $\mathrm{GGF}^{11}$. There are many factors responsible for it after LRYGB (Table 3). Non-divided RYGB procedures, as said, have been associated with an unacceptably high incidence of GGF because of breakdown of the staple line with reestablishment of continuity between the gastric segments. Technical variations with reinforcement of divided RYGB procedures with bands or rings to increase restriction and prevent stomal and pouch dilation are also related with a high incidence of GGF ${ }^{39}$. Intragastric migration of the band or ring with erosion of the staple line was implicated in the evolution of GGF in these procedures $^{24,26}$.

In the current era of divided RYGB, the majority of GGF are caused by poor surgical technique with failure to completely divide the stomach during pouch creation with maintenance of continuity between the pouch and remnant. In order to reduce the incidence of GGF some authors recommend a meticulous oversewing of staple lines, careful anastomotic technique with good bites of healthy tissue, avoidance of alimentary limb obstruction, and intraoperative confirmation of anastomosis integrity using methylene blue ${ }^{34}$.

Another common cause of GGF is an acute leak from the gastrojejunal anastomosis or the pouch staple-line disruption, which is reported in up to $4.3 \%$ of patients after LRYGB ${ }^{30}$.

Malfunctioning of linear staplers can also occur, although this complication has become uncommon with the advent of more sophisticated devices ${ }^{25}$.
TABLE 3 - Pathogenesis of gastro-gastric fistula after laparoscopic Roux-en-Y gastric bypass

\begin{tabular}{|c|c|}
\hline Cause & Description \\
\hline Iatrogenic & $\begin{array}{l}\text { Poor surgical technique } \\
\text { Incomplete gastric transection }\end{array}$ \\
\hline $\begin{array}{l}\text { Anastomotic } \\
\text { leak }\end{array}$ & $\begin{array}{c}\text { Pouch staple line disruption } \\
\text { Gastrojejunal anastomotic disruption } \\
\text { Coagulation injury } \\
\text { Ischemic necrosis due to foreign body: VBG, LAGB } \\
\text { Incomplete gastric transection }\end{array}$ \\
\hline $\begin{array}{l}\text { Operation } \\
\text { type }\end{array}$ & Non-divided gastric bypass \\
\hline $\begin{array}{l}\text { Marginal } \\
\text { ulcer, } \\
\text { perforation }\end{array}$ & $\begin{array}{l}\text { Tissue ischemia } \\
\text { Staple migration }\end{array}$ \\
\hline $\begin{array}{l}\text { Foreign } \\
\text { body } \\
\text { erosion }\end{array}$ & $\begin{array}{c}\text { Use of non-absorbable suture material } \\
\text { Preanastomotic rings in banded gastric } \\
\text { bypass } \\
\text { Bovine pericardial strips }\end{array}$ \\
\hline $\begin{array}{l}\text { Natural } \\
\text { tendency }\end{array}$ & Natural gastric migration to reattach to the remnant \\
\hline
\end{tabular}

Various techniques have been used to reduce the occurrence of pouch staple-line leak and GGF, including jejunal and/ or omental interposition, suture reinforcement of the staple line, vapor-heated fibrin sealant, and more recently, bovine pericardial strips $\mathrm{s}^{5,7,11,20}$.

All patients with a GGF should be treated with a proton pump medication regardless of symptoms, with the addition of sucralfate for concomitant marginal ulceration and/or stricture. The surgery must be considered when medical management failed in a symptomatic patient, when there is weight regain with non-resolution of comorbidity, recurrent or non-healing gastrojejunal ulceration with persistent abdominal pain and/or hemorrhage, and recurrent gastrojejunal anastomosis stricture.

Currently, there is no accepted surgical technique to manage symptomatic GGF. One possible approach is to perform a remnant gastrectomy with trimming of the gastric pouch and excision or exclusion of the fistulous tract. This approach has the advantage that does not interfere with the gastrojejunal anastomosis.

The pouch size determines the need for fistula excision or exclusion. In the presence of an adequately sized small pouch, the tract can be excluded by vertical transection of the gastric remnant lateral to the fistula. It is important to excise as much of the antrum as possible to avoid the creation of a retained antrum and the theoretical risk of hypergastrinemia. Therefore, the distal stomach is transected just proximal to the pylorus. Remnant gastrectomy can be performed successfully by a laparoscopic approach in the majority of patients.

Excision of the gastrojejunal anastomosis with re-anastomosis is required in the presence of significant marginal ulceration with stomal stenosis or prior RYGB, where complete pouch revision is required.

In other cases the identification, isolation and transection of the fistulous tract with an Endo GIA stapler could be enough to solve $\mathrm{it}^{20}$. And also, recent reports of transgastric and endoscopic approaches using a through-the-scope endoclip repair have attracted some interest. However, there are limited data on the long-term durability or overall efficacy of these repairs.

In summary, GGF formation can complicate divided LRYGB. Symptoms may include: weight loss or weight gain, intractable marginal ulceration, recurrent upper gastrointestinal hemorrhage and abdominal pain. Asymptomatic GGF can be managed conservatively. There is no standardized surgical treatment approach for symptomatic GGF. The range of therapeutic options includes from remnant gastrectomy to isolation and transection of the fistulous tract. 
CONCLUSIONS

Knowledge on strategies on how to reduce the risk and incidence of complications must be acquired, and every surgeon must be familiar with these complications in order to achieve an early recognition and better intervention.

\section{REFERENCES}

1. Ahmad J, Martin J,Ikramuddin S, SchauerP, Slivka A (2003) Endoscopic balloon dilation of gastroenteric anastomotic stricture laparoscopic gastric bypass. Endoscopy 35: 725-728

2. Ahmed AR, Rickards G, Husain $S$, et al. Trends in internal hernia incidence after laparoscopic Roux-en-Y gastric bypass. Obes Surg 2007;17(12):1563-6

3. Alasfar F, Sabnis AA, Liu RC, et al. Stricture rate after laparoscopic Roux-en-Ygastric bypass with a 21-mm circularStapler:The Cleveland Clinic Experience. Med Princ Pract 2009;18:364-7.

4. Aquafresca PA, Palesmo M, Rogula T, Duza GE, Serra E. Complicações cirúrgicas tardias após by-pass gástrico: revisão da literatura. Arq Bras Cir Dig. 2015;28(2):

5. Behrns KE, Smith CD, Sarr MG. Prospective evaluation of gastric acid secretion and cobalamin absorption following gastric bypass for clinically severe obesity. Dig Dis Sci 1994;39(2):315-20

6. Ben-Meir ASI, Patterson L, Schreiber H, Salomone M, Sharma K, Kumar A, Marshall J (2005) Cigarette smoking but not NSAID or alcohol use or comorbidities is associated with anastomotic ulcers in Roux-en-Y gastric bypass (RYGB) patients. Surg Obes Relat Dis 1:263-264

7. Blachar A, Federle MP (2002) Gastrointestinal complications of laparoscopic Roux-en-Y gastric bypass surgery in patients who are morbidly obese: findings on radiography and CT. AJR Am J

8. Capella RF, Iannace VA, Capella JF. Bowel obstruction after open and laparoscopic gastric bypass surgery for morbid obesity. J Am Coll Surg 2006;203(3): 328-35.

9. Champion JK, Williams M. Small bowel obstruction and internal hernias after laparoscopic Roux-en-Y gastric bypass. Obes Surg 2003;13(4):596-600.

10. Csendes A, Burgos AM, Altuve J, et al. Incidence of marginal ulcer 1 month and 1 to 2 years after gastric bypass: a prospective consecutive endoscopic evaluation of 442 patients with morbid obesity. Obes Surg 2009;19:135-8

11. Cucchi SG, Pories WJ, MacDonald KG, et al. Gastrogastric fistulas. A complication of divided gastric bypass surgery. Ann Surg 1995;221:38791.

12. Daylami R, Rogers AM, King TS, etal. Accuracy of uppergastrointestinal swallow study in identifying strictures after laparoscopic gastric bypass surgery. Surg Obes Relat Dis 2008;4(2):96-9.

13. El-Hayek K, Timratana P, Shimizu H, Chand B. Marginal ulcer after Roux-en-Y gastric bypass: what have we really learned? Surg Endosc. 2012 Oct;26(10):2789-96. Epub 2012 Apr 28

14. Fisher BL, Atkinson JD, Cottam D. Incidence of gastroenterostomy stenosis in laparoscopic Roux-en-Y gastric bypass using 21- or 25-mm circular stapler: a randomized prospective blinded study. Surg Obes Relat Dis 2007;3(2):176-9.

15. Frutos MD, Lujan J, García A, et al. Gastrojejunal anastomotic stenosis in laparoscopic gastric bypass with a circular stapler (21 $\mathrm{mm}$ ): incidence, treatment and long-term follow-up. Obes Surg 2009;19(12):1631-5

16. Garza E Jr, Kuhn J, Arnold D, et al. Internal hernias after laparoscopic Roux-en-Y gastric bypass. Am J Surg 2004;188(6):796-800

17. Go MR, Muscarella P 2nd, Needleman BJ, Cook CH, Melvin WS (2004) Endoscopic management of stomal stenosis after Roux-en- $Y$ gastric bypass. Surg Endosc 18: 56-59

18. Goitein D, Papasavas PK, Gagne D, et al. Gastrojejunal strictures following laparoscopic Roux-en-Y gastric bypass for morbid obesity. Surg Endosc 2005;19:628-32.

19. Gonzalez R, Lin E, Venkatesh KR, et al. Gastrojejunostomy during laparoscopic gastric bypass: analysis of 3 techniques. Arch Surg 2003;138(2):181-4
20. Higa KD, Boone KB, Ho T (2000) Complications of the laparoscopic Roux-en-Y gastric bypass: 1,040 patients—what have we learned? Obes Surg 10:509-513

21. Huang CS, Forse RA, Jacobson BC, et al. Endoscopic findings and their clinical correlations in patients with symptoms after gastric bypass surgery. Gastrointest Endosc 2003;58(6):859-66.

22. Jirapinyo $P$, Watson RR, Thompson CC. Use of a novel endoscopic suturing device to treat recalcitrant marginal ulceration. Gastrointest Endosc. 2012 Aug;76(2):435-9. doi:10.1016/j.gie.2012.03.681. Epub 2012 May 31

23. Kurata JH, Nogawa AN. Meta-analysis of risk factors for peptic ulcer. Nonsteroidal antiinflammatory drugs, Helicobacter pylori, and smoking. J Clin Gastroenterol 1997;24(1):2-17.

24. Mason EE, Munns JR, Kealey GP, et al. Effect of gastric bypass on gastric secretion. 1977. Surg Obes Relat Dis 2005;1(2):155-60 [discussion: 161-2].

25. MasonEE.Ulcerogenesisinsurgeryforobesity.Obes Surg1996;6(2):180-1.

26. Mathew A, Veliuona MA, DePalma FJ, et al. Gastrojejunal stricture after gastric bypass and efficacy of endoscopic intervention. Dig Dis Sci 2009;54:1971-8.

27. Nguyen NT, Stevens CM, Wolfe BM. Incidence and outcome of anastomotic stricture after laparoscopic gastric bypass. J Gastrointest Surg 2003;7:997-1003.

28. Papasavas PK, Caushaj PF, McCormick JT, Quinlin RF, Hayetian FD, Maurer J, Kelly JJ, Gagne DJ (2003) Laparoscopic management of complications following laparoscopic Roux-en-Y gastric bypass for morbid obesity. Surg Endosc 17: 610- 614

29. Papasavas PK, Gagne' DJ, Donnelly PE, etal. Prevalence of Helicobacter pylori infection and value of preoperative testing and treatment in patients undergoing laparoscopic Roux-en-Y gastric bypass. Surg Obes Relat Dis 2008;4(3):383-8

30. Printen KJ, Scott D, Mason EE. Stomal ulcers after gastric bypass. Arch Surg 1980;115(4):525-7.

31. Ramos AC, Silva AC, Ramos MG, Canseco EG, Galvão-Neto Mdos P, Menezes Mde A, Galvão TD, Bastos EL. Simplified gastric bypass: 13 years of experience and 12,000 patients operated. Arq Bras Cir Dig. 2014;27 Suppl 1:2-8.

32. Rasmussen JJ, FullerW, Ali MR. Marginal ulceration afterlaparoscopic gastric bypass: an analysis of predisposing factors in 260 patients. Surg Endosc 2007;21(7):1090-4.

33. Rogula T, Yenumula PR, Schauer PR. A complication of Rouxen-Y gastric bypass: intestinal obstruction. Surg Endosc. 2007 Nov;21(11):1914-8. Epub 2007 Sep 22.

34. Ryskina KL, Miller KM, Aisenberg J, et al. Routine management of stricture after gastric bypass and predictors of subsequent weight loss. Surg Endosc 2010; 24(3):554-60

35. Sacks BC, Mattar SG, Qureshi FG, et al. Incidence of marginal ulcers and the use of absorbable anastomotic sutures in laparoscopic Roux-en-Y gastric bypass. Surg Obes Relat Dis 2006;2(1):11-6.

36. Sapala JA, Wood MH, Sapala MA, et al. Marginal ulcer after gastric bypass: a prospective 3-year study of 173 patients. Obes Surg 1998;8: 505-16.

37. SchirmerB, ErenogluC, MillerA. Flexibleendoscopyinthemanagement of patients undergoing Roux-en-Y gastric bypass. Obes Surg 2002;12:634-8.

38. Schneider C, Cobb W, Scott J, Carbonell A, Myers K, Bour E. Rapid excess weight loss following laparoscopic gastric bypass leads to increased risk of internal hernia. Surg Endosc. 2011 May;25(5):15948. doi: 10.1007/s00464-010-1444-9. Epub 2010 Nov 12.

39. Sugerman HJ. Gastric bypass surgery for severe obesity. Semin Laparosc Surg 2002;9(2):79-85.

40. Swartz DE, Gonzalez V, Felix EL. Anastomotic stenosis after Rouxen-Y gastric bypass: a rational approach to treatment. Surg Obes Relat Dis 2006;2(6):632-6 [discussion: 637].

41. Tucker ON, Szomstein S, Rosenthal RJ. Surgical management of gastro-gastric fistula after divided laparoscopic Roux-en-Y gastric bypass for morbid obesity. J Gastrointest Surg 2007;11:1673-9.

42. Wendling MR, Linn JG, Keplinger KM, Mikami DJ, Perry KA, Melvin WS, Needleman BJ. Omental patch repair effectively treats perforated marginal ulcer following Roux-en-Y gastric bypass. Surg Endosc. 2013 Feb;27(2):384-9. doi: 10.1007/s00464-012-2492-0. Epub 2012 Aug 31. 